\title{
Evaluating the Resilience of Energy Supply Systems at the Example of a Single Family Dwelling Heating System
}

\author{
Anne Senkel Carsten Bode Gerhard Schmitz \\ Institute of Engineering Thermodynamics, Hamburg University of Technology, Denickestr. 17, 21073 Hamburg, \\ Germany, \{anne.senkel, c.bode, schmitz\}@tuhh. de
}

\begin{abstract}
Since the 1980s, the term "resilience" occurs more and more frequently in energy system analysis. However, the consideration and definition of the term primarily occurs in a qualitative way. This papers introduces a quantitative method to assess an energy system's resilience by using physical key figures to reflect the maintained functionality during and after a disturbance.

The presented method is used to evaluate the resilience of a heating system of a single family dwelling when its pump or boiler fails. It can be shown that the introduced resilience index mirrors the drop of the system's functionality and is also able to point out weak spots and the most efficient system improvements. This provides the foundation of comparing the resilience of complex systems even though it is important to pay attention to comparable assessment settings.
\end{abstract}

Keywords: Resilience, Energy Supply Systems Assessment, Heating

\section{Introduction}

By publishing its special report on the impact of global warming of $1.5^{\circ} \mathrm{C}$, the IPCC stressed the necessity to decarbonize the energy sector in the medium-term (Allen et al., 2018). On the other hand, already today the increasing integration of renewable energies in the electricity sector leads to rising numbers of interventions and adaptions of the operational planning of power plants to avoid overloading power line sections. In Germany, these measures lead to the "redispatch" of $20.438 \mathrm{GWh}$ in 2017, compared to $4.956 \mathrm{GWh}$ in 2012 (Bundesnetzagentur, 2018). Therefore, not only costs and efficiency, but also the security and resilience of the energy system have to be taken into account while moving towards a sustainable energy supply.

The term resilience originates from the Latin word "resilire" (jumping back, rebounding, returning) and was already used in the $17^{\text {th }}$ century to describe physical counter-reactions (Gößling-Reisemann, Hellige and Thier, 2018). Later, it also became established in psychology, sociology and ecology. However, a universal definition of resilience has not been established yet. In general, the definition by Holling
(1973) which defines resilience as a "measure of the persistence of systems and of their ability to absorb change and disturbance", is used widely.

Caused by the discussions about safety of nuclear power plants and climate change, resilience increasingly occurs in the energy sector since the 1980s. Since then, several research projects have focused on defining resilience in the context of energy systems.

A general overview of the historical development of the resilience term and guidelines for designing a resilient system are given by Gößling-Reisemann, Hellige and Thier (2018). Fichter et al. (2010) include vulnerability analysis as analytical category in their resilience considerations. Resilience itself is used as a normative category and characterized by introducing system structures that increase resilience. Several ways of qualitative analysis are also provided by (Thoma, 2014) who approaches resilience as a holistic concept including technological, social and economic aspects. Further qualitative assessments of resilience were conducted by Roege et al. (2014), Molyneaux et al. (2012) and Madni and Jackson (2009).

A quantitative evaluation method was presented by Cimellaro et al. (2009) who used a functionality curve to evaluate the dimensions of resilience rapidity, redundancy, robustness and resourcefulness for earthquake disasters. Francis and Bekera (2014) extend this approach by implementing the fragility of the system. A similar approach was conducted by Nan and Sansavini (2017) who additionally considered the performance loss. To assess the resilience of energy systems in this work, the approaches of Francis and Bekera (2014) and Nan and Sansavini (2017) are adapted and the resulting definition presented in the following section.

\section{Definition of the Resilience Index}

To be able to evaluate the resilience of an energy system, it is necessary to define a key figure that reflects the performance of the system. Nan and Sansavini (2017) call this the "measure of performance" (MOP) while Francis and Bekera (2014) use the term "performance level". Since these values are fictional quantities, this approach needs to be adapted for the 
assessment of the results of dynamic simulations. Therefore, a physical value needs to be found. For the electricity sector, this could be for example the grid frequency. For the heating sector, the supply or the room temperature is more suitable.

Each of these physical key figures $x$ is defined by a set point $x_{\text {set }}$ and a tolerance band $\left[x_{\min }, x_{\max }\right]$ in which deviations of $x$ are tolerated. In Figure 1, a characteristic plot of such a key figure is depicted.

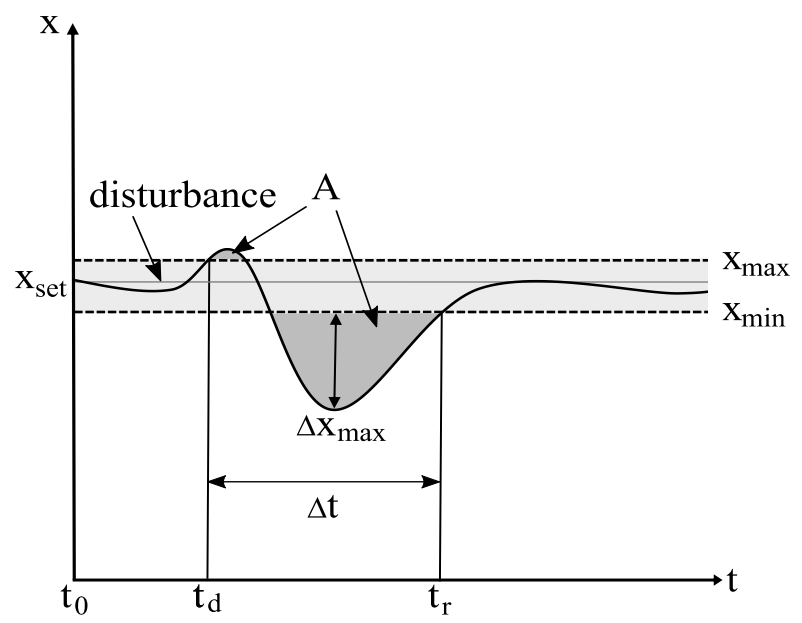

Figure 1. Characteristic course of a key figure in a disturbed system.

Following the definitions of Francis and Bekera (2014) and Nan and Sansavini (2017), the system's restorative, absorptive and adaptive capacity can be evaluated by assessing the progression of this key figure.

For the restorative capacity, the Recovery Time RT of a system will be computed as,

$$
R T=\frac{t_{\mathrm{r}}-t_{\mathrm{d}}}{\Delta t_{\text {norm }}}
$$

with $t_{\mathrm{d}}$ as the point in time when the key figure leaves the tolerance band for the first time, and $t_{\mathrm{r}}$ as the point in time when the key figure returns into the tolerance band and remains permanently within it. While Nan and Sansavini (2017) divide this time period by the deviation of the key figure, this paper introduces $\Delta t_{\text {norm }}$ as normalization time to achieve dimensionless values.

For the absorptive capacity, Francis and Bekera (2014) and Nan and Sansavini (2017) both propose to examine the Maximum Deviation MD of the key figure, $\Delta x_{\max }$. Since a tolerance band was introduced, this approach is adapted to only consider the deviation of $x$ from the minimum or maximum value of the tolerance band (c.f. Figure 1). Therefore, $\Delta x$ is defined as,

$$
\Delta x= \begin{cases}x-x_{\max } & \text { if } x \geq x_{\max } \\ 0 & \text { if } x_{\min }<x<x_{\max } \\ x_{\min }-x & \text { if } x \leq x_{\min }\end{cases}
$$

which leads to $\Delta x=0$ for deviations within the tolerance band so that normal fluctuations are not punished. The maximum of $\Delta x$ is defined as $\Delta x_{\max }$ and used in the following considerations. While Francis and Bekera (2014) divide this value with the set point $x_{\text {set }}$, Nan and Sansavini (2017) use no weight factor but weight their MOP at the beginning resulting in MOPs between 0 and 1 . For the introduced physical key figures, it is therefore necessary to define a normalization deviation $\Delta x_{\text {norm }}$ as well,

$$
M D=\frac{\Delta x_{\max }}{\Delta x_{\text {norm }}}
$$

Additionally, Nan and Sansavini (2017) introduce the Performance Loss $P L$ as an indicator of the absorptive capacity,

$$
P L=\frac{\int_{t_{\mathrm{d}}}^{t_{\mathrm{r}}} \Delta x d t}{A_{\text {norm }}}
$$

which basically represents the area between the actual course of the key figure and its set point. This figure is also adapted to fit to the introduction of the tolerance band and therefore defined as area between tolerance band and the course of the key figure (depicted as $A$ in Figure 1). When using this definition in combination with physical values, a weight factor $A_{\text {norm }}$ will be necessary as well.

Finally, both papers introduce a Recovery Ability $R A$ to evaluate the system's adaptive capacity,

$$
R A=\frac{x\left(t_{\mathrm{r}}\right)}{x\left(t_{0}\right)}
$$

where a higher system's functionality after the disturbance $x\left(t_{\mathrm{r}}\right)$ than before $x\left(t_{0}\right)$ indicates that the system learned from the incidence and adapted to it. However, this index is not suitable when examining physical key figures. For example, a higher net frequency would not indicate a better system's performance but rather further instabilities.

By combining the recovery time, the maximum deviation and the performance loss, an Irresilience Index IRI is introduced,

$$
I R I=R T \cdot M D \cdot P L
$$

and with this a Resilience Index $R I$ is defined,

$$
R I=\frac{1}{1+I R I}
$$

where $R I=0$ represents a completely irresilient system and $R I=1$ a resilient system. This general definition can be applied to any energy supply system (electricity, heat, gas, etc.) as long as an appropriate key figure for which a tolerance band can be defined, is used. 


\section{Case Study of a Single Family Dwelling}

In the following section the introduced resilience index will be applied to a heating system of a single family dwelling (SFD).

\subsection{Model Structure}

The model of the heating system was built using Modelica ${ }^{\circledR}$ (Modelica Association, 2019) in Dymola (Dassault Systèmes, 2018) using the TransiEnt Library (Andresen et al., 2015; Hamburg University of Technology, 2017) and the ClaRa Library (Brunnemann et al., 2012; Hamburg University of Technology, TLKThermo GmbH, XRG Simulation, 2012) for the components of the heating system. The heating demand of the single family dwelling is modeled using the Buildings Library (Wetter et al., 2014). Therefore the heat exchange with the environment is considered at a low resolution by aggregating the heat transfer through the walls and windows, the heat capacity and the heat gains and losses through solar irradiance, ventilation and internal sources each in one instance (Senkel, 2017). The icon layer of the heating system model is depicted in Figure 2.

In the heating system, the heat is produced by a gas boiler and transferred to the building through a heat exchanger. The produced heat flow of the boiler is set to obtain the supply temperature given by the heating curve of the system. To adjust the heat transferred to the building, a thermostat is integrated that varies its opening in order to obtain a room temperature of $22{ }^{\circ} \mathrm{C}$ (according to EN 15251 (European Commitee for Standardization, 2007)). The installed pump regulates its mass flow to keep a constant pressure loss resulting in a smaller mass flow when the thermostat is closing in.
Furthermore an expansion vessel is integrated to balance the pressure in the system. The most important parameters of the system are collected in Table 1.

The following results were simulated with the solver Dassl in a 15-minutes resolution with a tolerance of 0.0001 .

Table 1. Parameters of the heating system.

\begin{tabular}{lr}
\hline Parameter & \multicolumn{1}{c}{ Value } \\
\hline Set room temperature & $22{ }^{\circ} \mathrm{C}$ \\
$\begin{array}{l}\text { Nominal supply/return } \\
\text { temperature }\end{array}$ & $60 / 40{ }^{\circ} \mathrm{C}$ \\
Nominal mass flow & $0.2 \mathrm{~kg} / \mathrm{s}$ \\
Nominal pressure & $1 \mathrm{bar}$ \\
$\begin{array}{l}\text { Nominal heat flow of gas boiler } \\
\text { Heat transfer coefficient of the }\end{array}$ & $7 \mathrm{~kW}$ \\
building envelope & $0.4 \mathrm{~W} /\left(\mathrm{m}^{2} \mathrm{~K}\right)$ \\
$\begin{array}{l}\text { Heat transfer coefficient of the } \\
\text { windows }\end{array}$ & $3 \mathrm{~W} /\left(\mathrm{m}^{2} \mathrm{~K}\right)$ \\
$\begin{array}{l}\text { Floor area } \\
\text { Window area }\end{array}$ & $100 \mathrm{~m}^{2}$ \\
Minimal outdoor temperature & $16 \mathrm{~m}^{2}$ \\
\hline
\end{tabular}

\subsection{Scenarios}

First, the shown system is simulated with the weather data of Hamburg in the period between January $30^{\text {th }}$ and February $2^{\text {nd }}, 2012$ (Lange, 2014). This time period was selected due to the occurring low outside temperatures which lead to an enhancement of the considered effects. According to EN 15251 (European Commitee for Standardization, 2007), an operational temperature of $22{ }^{\circ} \mathrm{C}$ within a tolerance band of $\pm 2 \mathrm{~K}$ is recommended for ambient temperatures below $16{ }^{\circ} \mathrm{C}$. Figure 3 shows
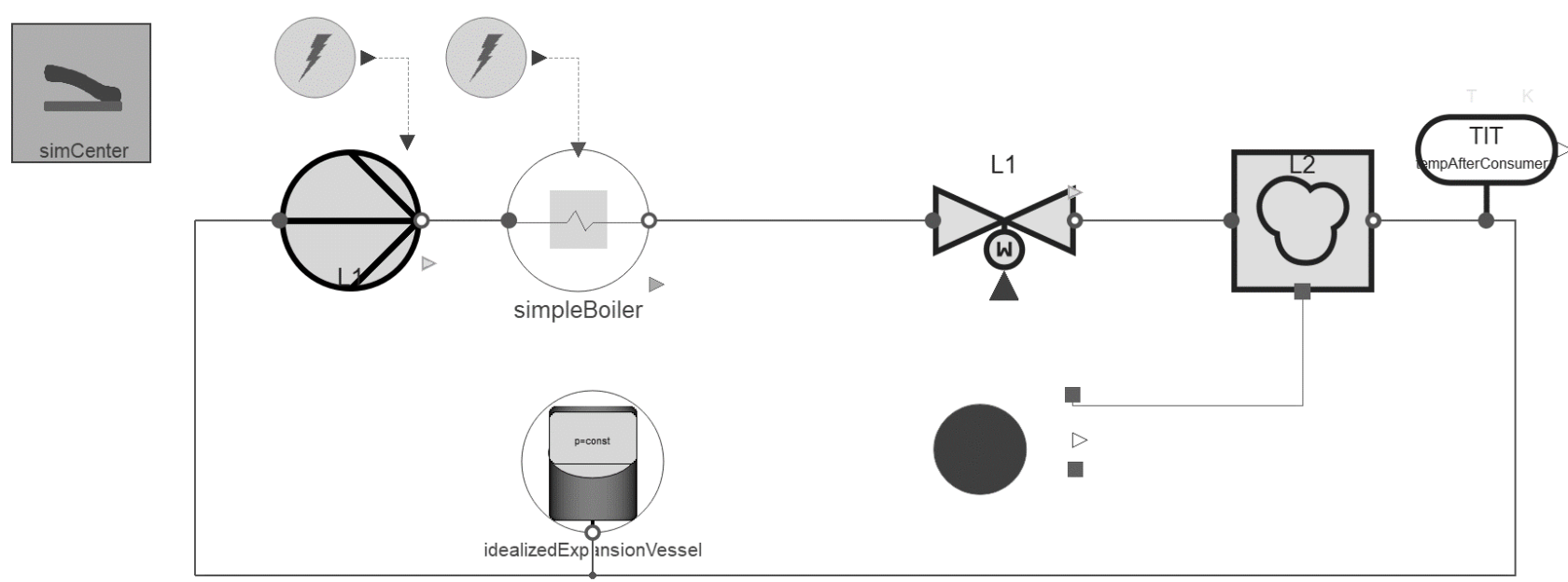

Figure 2. Model structure of Reference System. 
that the system is able to provide this service offering as long as it is undisturbed. In this case the temperature only slightly varies from its set point due to fluctuations in the outside temperature and solar irradiance.
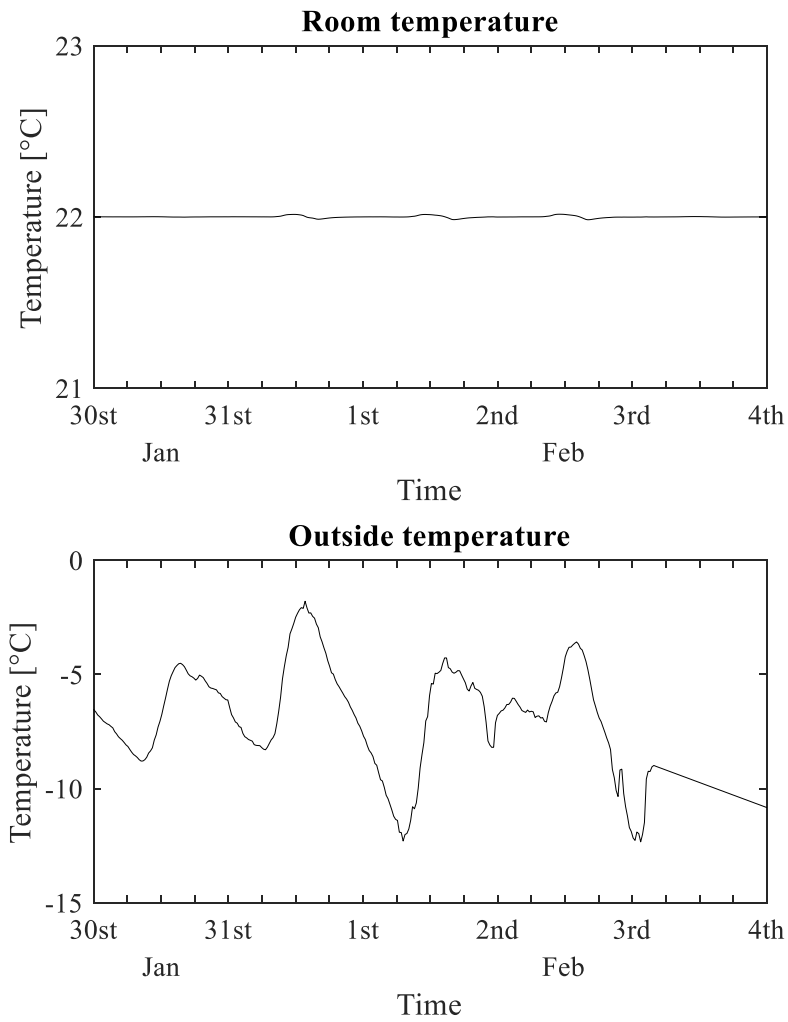

Figure 3. Room temperature and outside temperature without disturbance.

The first considered improvement (System 1) is to lower the house's heat losses by installing windows with a lower heat transfer coefficient $\left(k_{\text {win }}=1.3 \mathrm{~W} /\left(\mathrm{m}^{2} \mathrm{~K}\right)\right)$.

The second improvement (System 2) involves a change of the heating system by installing a hot water storage vessel $\left(V_{\text {stor }}=0.6 \mathrm{~m}^{3}\right)$ as shown in Figure 4 . This also leads to changes in the control of the heating system. Therefore, the heat flow of the boiler is regulated to obtain a temperature of $60{ }^{\circ} \mathrm{C}$ in the upper part of the hot water storage. The mass flow in the boiler circuit is regulated by a pump which adapts its power to obtain a maximum boiler outlet temperature of $60{ }^{\circ} \mathrm{C}$. In the consumer circuit, a mixing valve is integrated to mix cool return water with the hot water of the storage in order to meet the supply temperature given by the heating curve. The control of the pump in the consumer circuit and the thermostat are left untouched.

In the following simulations, the systems are disturbed by a failure of the boiler or the supply pump (see also Figure 2 and Figure 4, indicated by the lightning symbol). Both failures occur in the first twelve hours of February, $1^{\text {st }}$.

\subsubsection{Scenario Consumer Pump Failure}

When the pump shuts down, no hot water flows through the heat exchanger. Hence, no heat can be transferred to the building and the room temperature of the reference systems drops drastically due to the cold outside temperature (Figure 5).

When looking at System 1 during the pump failure, one can observe that due to the improved insulation the temperature drops less than in the reference case. Furthermore, it becomes obvious, that the system recovers faster than in the reference case since the heat loss to the surroundings is lower, resulting in a shorter reheating phase.

For the failure of the consumer pump, System 2 shows a similar temperature drop as in the reference case since the house itself remains without heat supply and the heat losses to the surroundings are due to the same insulation as high as in the reference case. After the disturbance, the boiler inlet temperature is higher

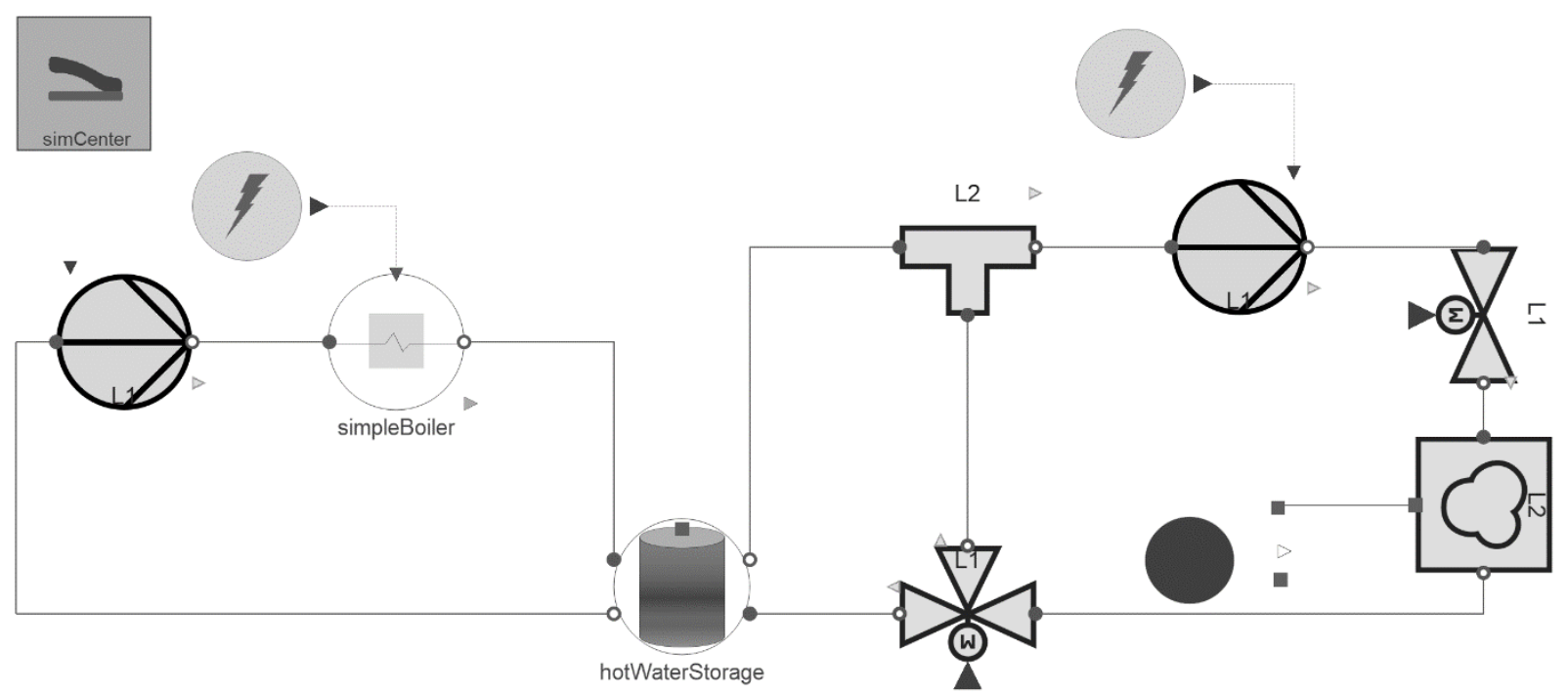

Figure 4. Model structure of System 2. 
since the boiler is fed from the hot water storage in which the cold return water is mixed with the warmer water stored at the bottom of the tank. Additionally, the supply water is mixed with hotter water in the top of the storage vessel. Both effects lead to higher supply temperatures in System 2 than in the reference system which is why the set point of the room temperature is reached faster in this system.

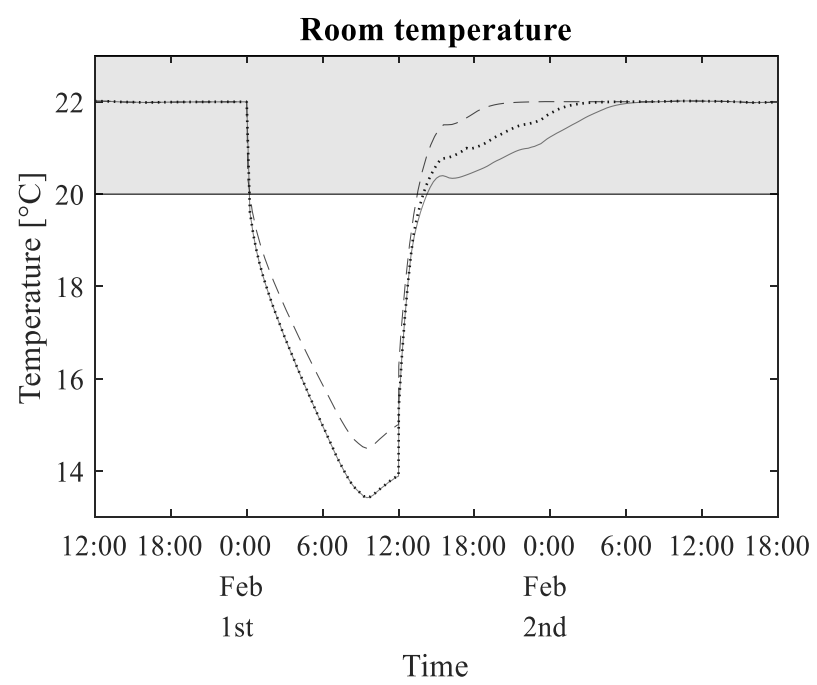

Figure 5. Temperature profiles during consumer pump failure (shaded: tolerance band, solid: Reference System, dashed: System 1, dotted: System 2).

\subsubsection{Scenario Boiler Failure}

The failure of the boiler in the reference system results in a less drastic temperature drop (Figure 6) since the heat exchanger is still supplied with warm water. However, after transferring heat to the building, the water is not reheated by the boiler which leads to gradually declining supply and room temperatures. Because of the lower supply water temperature, one can also observe that the heating system needs longer to recover after the disturbance since the boiler inlet temperature is lower than when the pump was shut down.

For System 1, the same effects occur as when the pump failed: due to the improved insulation the temperature drops less and the system recovers faster.

In System 2, when the boiler shuts down, the supply water stays hotter for a longer term than in the reference system since it is fed by the stored hot water. However, the temperature in the tank gradually declines as well since the cold return water is led into it and thus the room temperature also declines. When comparing this temperature behavior with System 1, one can notice that System 2 needs longer to recover. This fact also leads back to the higher heat transfer coefficient of the windows and the therefore higher heat losses in System 2. Furthermore, the hot boiler outlet water is mixed with the colder storage water which leads to a colder temperature at the radiator inlet.

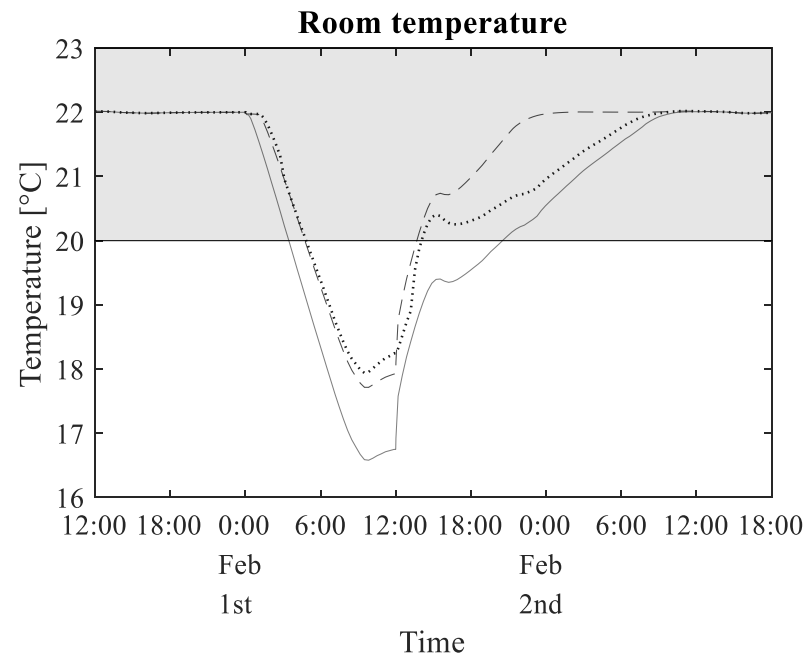

Figure 6. Temperature profiles during boiler failure (shaded: tolerance band, solid: Reference System, dashed: System 1, dotted: System 2).

\subsubsection{Behavior of a Combined System}

After focusing on single improvements in the considered system, a system combining both improvements was simulated with the presented disturbances. The temperature profiles are compared with those of System 1 and 2 in Figure 7 and Figure 8.

When considering the pump failure, it becomes once again obvious that the most important effect during this disturbance is the heat loss of the building. Accordingly, the temperature profile of the Combined System matches that of System 1. Installing a storage vessel in the system has no big impact when regarding this disturbance.

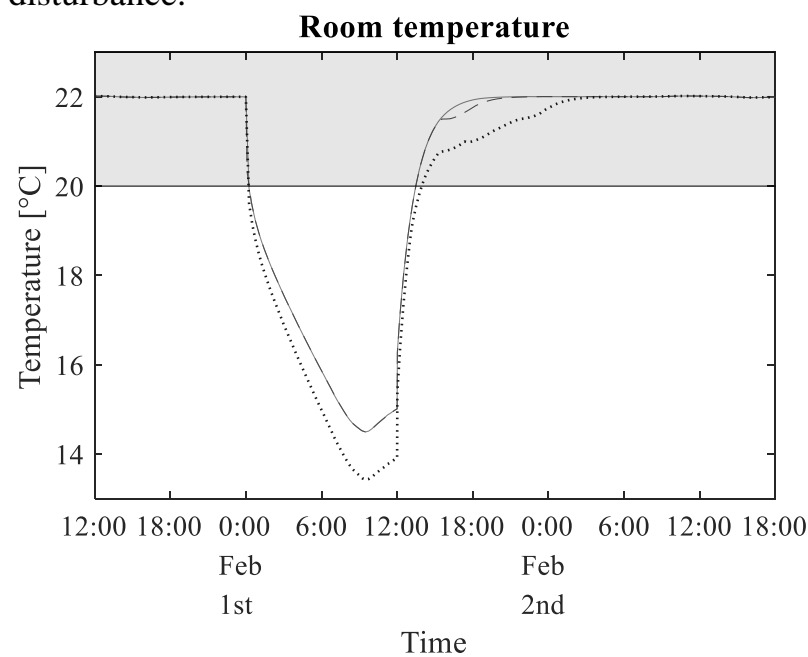

Figure 7. Temperature profiles during consumer pump failure (shaded: tolerance band, solid: Combined System, dashed: System 1, dotted: System 2).

When considering the boiler failure, the positive effects of lower heat losses due to better window insulation and a longer heat supply due to the installed heat storage add up to a significantly lower temperature drop and a faster system recovery. 


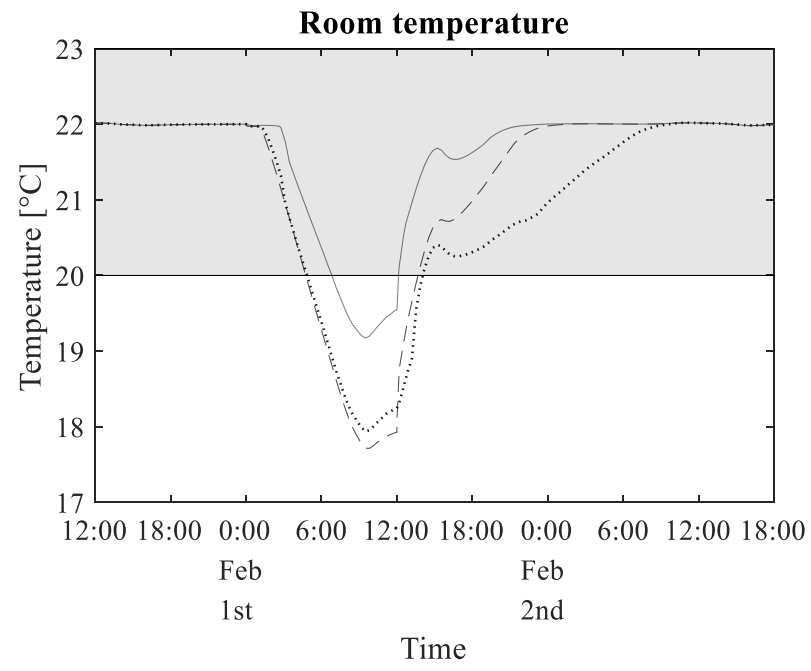

Figure 8. Temperature profiles during boiler failure (shaded: tolerance band, solid: Combined System, dashed: System 1, dotted: System 2).

\subsection{Discussion of the Resilience Index}

According to eq. (5), the resilience indices are computed for the presented systems under the influence of the two disturbance scenarios with and without considering the performance loss $P L$. The normalization values used are $\Delta x_{\text {norm }}=1 \mathrm{~K}, \Delta t_{\text {norm }}=6 \mathrm{~h}$ and $A_{\text {norm }}=\Delta x_{\text {norm }}$. $\Delta t_{\text {norm }}=6 \mathrm{Kh}$. The results can be found in Table 2 and Table 3 .

Overall, it is obvious that large temperature drops and recovery times lead to small resilience indices which shows that the resilience index reliably reflects the resistance and recovery ability of the system.

In general, the resilience indices are rather low which is plausible since the considered system does not feature common qualitative resilience aspects like redundancy, buffer capacity or variety (refer to (Fichter et al., 2010) for more information). With regard to these low values, it should be noted that the absolute values of the indices are dependent on the choice of the normalization values. Therefore, it is important to only compare systems with the same normalization values since the results are otherwise distorted.

Table 2. Resilience indices for Reference System, System 1 and 2 and the Combined System during pump failure.

\begin{tabular}{|c|c|c|c|c|}
\hline System & Ref & 1 & 2 & Comb \\
\hline$\Delta x_{\max }[\mathrm{K}]$ & 6.6 & 5.5 & 6.6 & 5.5 \\
\hline$\Delta t[\mathrm{~h}]$ & 14.3 & 13.1 & 13.8 & 13.1 \\
\hline$P L[\mathrm{Kh}]$ & 57.8 & 46.7 & 57.6 & 46.7 \\
\hline w/PL & 0.01 & 0.02 & 0.01 & 0.02 \\
\hline w/o PL & 0.06 & 0.08 & 0.06 & 0.08 \\
\hline
\end{tabular}

Table 3. Resilience indices for Reference System, System 1 and 2 and the Combined System during boiler failure.

\begin{tabular}{|c|c|c|c|c|}
\hline System & Ref & 1 & 2 & Comb \\
\hline$\Delta x_{\max }[\mathrm{K}]$ & 3.4 & 2.3 & 2.1 & 0.8 \\
\hline$\Delta t[\mathrm{~h}]$ & 16.8 & 9.1 & 9.1 & 5 \\
\hline$P L[\mathrm{Kh}]$ & 26.5 & 12.7 & 12.3 & 2.9 \\
\hline w/ PL & 0.05 & 0.22 & 0.24 & 0.86 \\
\hline w/o PL & 0.09 & 0.21 & 0.24 & 0.6 \\
\hline
\end{tabular}

Furthermore, it is apparent that in all cases the installation of windows leads to an increase of resilience since this improvement counteracts to the main reason of the system's vulnerability, the poor insulation of the building. Accordingly, implying this improvement is most effective in regards to resilience matters.

Another general aspect that becomes evident, is that the resilience indices vary for the same system in accordance to the disturbance it is exposed to. Hence, one can derive that there is no "absolute" resilience index, especially when keeping in mind that the concept of resilience also contains the system's capability to keep its functionality up when facing unknown disturbances. Therefore, when investigating a system's resilience, it is not sufficient to only look at one disturbance. In fact, the significance of a resilience analysis rises with its number of considered incidents.

Especially when looking at the results for the pump failure, one notices that all considered systems show very low resilience indices. This is in line with the observation that all systems experience significant temperature drops since the heat transfer to the building is directly cut off when the pump is not working. Thus, using the resilience index, is not only helpful when comparing different systems with each other but it can also reveal weak points of an energy system which consequently need to be protected or backed up more than others.

The multiplication with the performance loss leads to a weighting of the severity of the deviation. Since small deviation will lead to performance losses that are smaller than the normalization value, higher resilience indices will be calculated for these cases. This effect can be retraced by looking at the resilience index for the Combined System during the boiler shut down. Large deviation, however, lead to performance losses bigger than the normalization values and therefore even smaller resilience indices, as can be seen in the results of the Reference System and System 1 and 2. 


\section{Conclusion and Outlook}

This paper introduces a definition of resilience for the assessment of energy supply systems by evaluating the maximum deviation, the recovery time and the performance loss of a system. Several approaches are presented and used to introduce a resilience index that can be applied to analyze dynamic simulation results as those produced by simulations in Modelica. This index was calculated for different heating system configurations of a single family dwelling.

It was shown that the use of the resilience index enables the comparison of two different system improvements. While System 1 focuses on the consumer side, System 2 changes the structure of the heating system.

To comprehend the development of the resilience index, a very simple example was chosen. However, the definition of the resilience index also allows the analysis of more complex systems and the efficient evaluation of proposed improvements.

The presented performance loss reflects a system's recovery phase more than only focusing on the deviation's amplitude and time outside the tolerance band. Thus, it is recommended to use this parameter when looking at systems that undergo pre-stable phases, to gain a more precise resilience evaluation. Additionally, the implementation of the performance loss leads to a weighting of the severity of deviations.

As shown, the presented resilience analysis enables further location of a system's weak points which helps to choose and initiate system improvements that are the most efficient in regard to increasing the resilience.

Nevertheless, as in many evaluation methods, great caution needs to be taken when setting the evaluation conditions. This means that the absolute values of the resilience indices depend on the chosen normalization values. On the one hand, this constitutes the risk of comparing indices that are not comparable. On the other hand, it provides the flexibility to set the normalization according to the considered system. Therefore, an energy system which supplies sensitive infrastructure, for example a hospital, can be rated using smaller normalization values than a system supplying a residential area.

In addition, the quantification of the resilience allows a calculation of the "costs" of resilience - with regards to financial but also environmental aspects. As a result, a statement of how much more money or $\mathrm{CO}_{2}$ emission lead to how much more resilience, can be made.

The introduced evaluation method deviates from methods in literature because it is not able to show a system's adaptive capability since further social, economic and political aspects have to be considered that cannot be integrated in the physically based simulation environment of Modelica. The only way to approach this aspect is to perform several simulations that integrate system changes that are caused by a disturbance and influence the resilience in future scenarios. However, the fact remains that dynamic, technically-based simulations are not able to reflect the whole spectrum of resilience. For this reason, an additional qualitative assessment is recommended.

Further research should focus on using the resilience index on more complex systems including integrated energy systems and the evolutions that are necessary for these kinds of systems. Hence, it is proposed to allocate one resilience index for each integrated sector and combine them into one overall index which will make it possible to evaluate complex system changes, e.g. a rising share of renewables, with regards to resilience aspects.

\section{Acknowledgements}

The authors greatly acknowledge the funding from the German Federal Ministry of Economic Affairs and Energy for the project "ResiliEntEE - Resilienz gekoppelter Energienetze mit hohem Anteil Erneuerbarer Energien" (ResilientEE - Resilience of integrated energy networks with a high share of renewable energies, project number: 03ET4048).

\section{Reference list}

Allen, M. et al. (2018) Global Warming of $1.5^{\circ} \mathrm{C}$ : An IPCC special report on the impacts of global warming of $1.5^{\circ} \mathrm{C}$ above pre-industrial levels and related global greenhouse gas emission pathways, in the context of strengthening the global response to the threat of climate change, sustainable development, and efforts to eradicate poverty. Geneva (sr15). Available at: http://www.ipcc.ch/ report/sr15/.

Andresen, L. et al. (2015) 'Status of the TransiEnt Library: Transient Simulation of Coupled Energy Networks with High Share of Renewable Energy', Proceedings Modelica Conference 2015, The 11th International Modelica Conference, September 21-23, 2015: Linköping University Electronic Press, pp. 695-705. doi: 10.3384/ecp15118695

Brunnemann, J. et al. (2012) 'Status of ClaRaCCS: Modelling and Simulation of Coal-Fired Power Plants with CO2 Capture', Proceedings of the 9th International MODELICA Conference, September 3-5, 2012, Munich, Germany, 9th International MODELICA Conference, Munich, Germany, Sept. 3-5, 2012: Linköping University Electronic Press, pp. 609-618. doi: 10.3384/ecp12076609

Bundesnetzagentur (2018) Redispatch. Available at: https://www.bundesnetzagentur.de/DE/Sachgebiete/ ElektrizitaetundGas/Unternehmen_Institutionen/ Versorgungssicherheit/Engpassmanagement/Redispatch/ redispatch-node.html.

Cimellaro, G.P. et al. (2009) Quantification of Disaster Resilience of Health Care Facilities. Buffalo.

Dassault Systèmes (2018) Dymola® (Version 2019). Vélizy-Villacoublay, France. Available at: https:// www.3ds.com/de/produkte-und-services/catia/produkte/ dymola/. 
European Commitee for Standardization (2007) EN 15251

2012-12, Indoor environmental input parameters for design and assessment of energy performance of buildings addressing indoor air quality, thermal environment, lighting and acoustics. Brüssel.

Fichter, K. et al. (2010) Theoretische Grundlagen für erfolgreiche Klimaanpassungsstrategien. Bremen.

Francis, R. and Bekera, B. (2014) 'A metric and frameworks for resilience analysis of engineered and infrastructure systems', Reliability Engineering \& System Safety, 121, pp. 90-103. doi: 10.1016/j.ress.2013.07.004

Gößling-Reisemann, S., Hellige, H.D. and Thier, P. (2018) The Resilience Concept: From its historical roots to theoretical framework for critical infrastructure design. Bremen (artec-paper 217). Available at: https://www.unibremen.de/fileadmin/user_upload/sites/artec/ Publikationen/artec_Paper/217_paper.pdf.

Hamburg University of Technology (2017) TransiEnt Library. Hamburg. Available at: https://www.tuhh.de/ transient-ee/en/.

Hamburg University of Technology, TLK-Thermo GmbH, XRG Simulation (2012) ClaRa - Power Plant Simulation. Hamburg, Braunschweig. Available at: https:// www.claralib.com/.

Holling, C.S. (1973) 'Resilience and Stability of Ecological Systems', Annual Review of Ecology and Systematics, 4(1), pp. 1-23. doi: 10.1146/annurev.es.04.110173.000245

Lange, I. (2014) Outdoor Temperatures, Hamburg Billwerder, 900s, 2012. Available at: https:// wettermast.uni-hamburg.de/.

Madni, A.M. and Jackson, S. (2009) 'Towards a Conceptual Framework for Resilience Engineering', IEEE Systems Journal, 3(2), pp. 181-191. doi: 10.1109/JSYST.2009.2017397

Modelica Association (2019) Modelica. Linköping. Available at: https://www.modelica.org/.

Molyneaux, L. et al. (2012) 'Resilience and electricity systems: A comparative analysis', Energy Policy, 47, pp. 188-201. doi: 10.1016/j.enpol.2012.04.057

Nan, C. and Sansavini, G. (2017) 'A quantitative method for assessing resilience of interdependent infrastructures', Reliability Engineering \& System Safety, 157, pp. 35-53. doi: 10.1016/j.ress.2016.08.013

Roege, P.E. et al. (2014) 'Metrics for energy resilience', Energy Policy, 72, pp. 249-256. doi: 10.1016/j.enpol.2014.04.012

Senkel, A. (2017) Vergleich verschiedener Arten der Wärmeverbrauchsmodellierung in Modelica. Master Thesis. Hamburg University of Technology.

Thoma, K. (2014) acatech STUDIE Resilien-Tech: „,Resilience-by-Design “: Strategie für die technologischen Zukunftsthemen. Freiburg.

Wetter, M. et al. (2014) Modelica Buildings Library.

Available at: https://simulationresearch.lbl.gov/modelica/ download.html, doi: 10.1080/19401493.2013.765506. 